Research Article

\title{
Partial Discharge in Capacitor Model at Low Temperature
}

\author{
M. Nemamcha ${ }^{1}$, L. Herous ${ }^{1}$, M. Remadnia ${ }^{*}, 1$, M. Kachi', P. Rain ${ }^{2}$ and J. P. Gosse ${ }^{2}$ \\ ${ }^{1}$ Laboratoire de Génie Electrique de Guelma (LGEG). Université de 8 mai 1945, B.P 401 - 24000, Guelma, Algérie. \\ ${ }^{2}$ LEMD - CNRS 38042, Grenoble, France.
}

Received 9 January 2009; Revised 1 July 2009; Accepted 22 August 2009

\begin{abstract}
The partial discharge plays an important role in the ageing and the rupture process of solid or mixed insulation systems. It has been recognized that the failure of this insulation can be joined to the presence of partial discharge often in inclusions sparkling. Liquid filled cavities can be considered as the most likely defects that can exist in capacitors. In this paper we describe the partial discharge evolution at low temperatures in all-PP film capacitors according to the time and the applied voltage. We distinguish two regimes of discharges for all the range of temperature and the low temperatures encourage the breakdown of capacitors at weak voltage, we assign this phenomenon to the increase of the viscosity of filling liquid.
\end{abstract}

Keywords: Partial Discharge, Breakdown, Polypropylene, Capacitors, Mixed Dielectrics.

\section{Introduction}

During the last decades, the development of electrostatic industry has been accompanied by a growing interest in understanding the phenomena that leads to the breakdown of equipments. Since, numerous studies have shown that the insulation can be submissive to transitional phenomena causing its progressive deterioration. One of the most important phenomena is the partial discharge [1-3]. Moreover, it is acknowledged that defects accidentally introduced in the manufacture of electrical equipment (failing of impregnation, hole in a film ...) can generate partial discharge. The mechanisms of conduction and breakdown concerning gas or solid insulation have been largely studied and the evaluation of characteristics of the partial discharge in the space and in the time is relatively well known. The study of partial discharge in mixed dielectric structures makes always the object of intense investigations. Indeed, mixed dielectric structures (solid-liquid) offer the advantage to have a best dielectric rigidity [4-6].

In the present work, we are interested in the effect of the temperature on the partial discharge evolution in the capacitor model, made of impregnated polypropylene films, and particularly the effect of the low temperatures on the time evolution of the discharge regime.

\section{Experimental Techniques}

The detection and measurement of partial discharge was carried out with a device manufactured at LEMD Grenoble [7]. This device uses the electrical and optical expressions of partial discharge.

It allows making measurement of discharge in the order of $0.05 \mathrm{pC}$ with minimum duration between two successive discharges is $330 \mathrm{~ns}$. The diagram of Figure 1 represents the basic circuit for the electric partial discharge detection. Partial discharge appearance in the study cell causes current flows through the external circuit. The current circulates in the RLC impedance that allows the suppression of low frequency component of the current $i$. The impulses resulting across the impedance have a time constant $\mathrm{RC}=40 \mathrm{~ns}$ (fig. 1 ). When a discharge is detected, its amplitude and its polarity as well as the instant of its appearance are measured. The phase of the discharge appearance is deduced from this instant. The device includes a thermostatic drying-room that reaches temperatures until $-40{ }^{\circ} \mathrm{C}$.

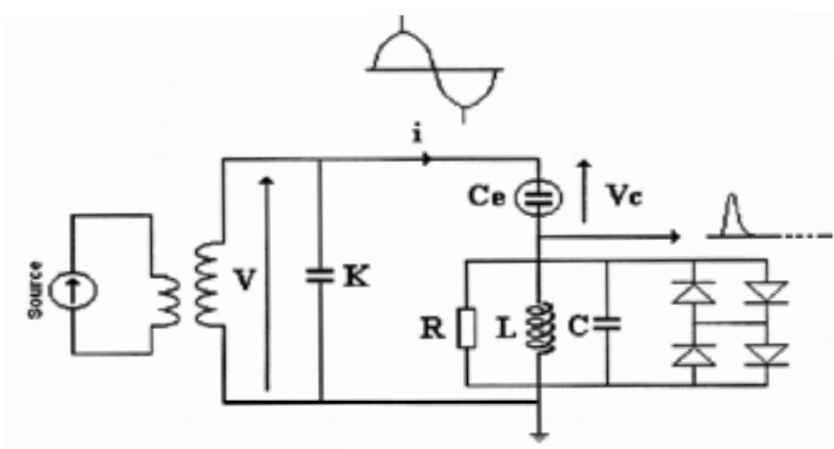

Figure 1. Principle of partial discharge measurement

* E-mail address: remadnia.m@gmail.com

ISSN: 1791-2377 (C) 2009 Kavala Institute of Technology. All rights reserved. 


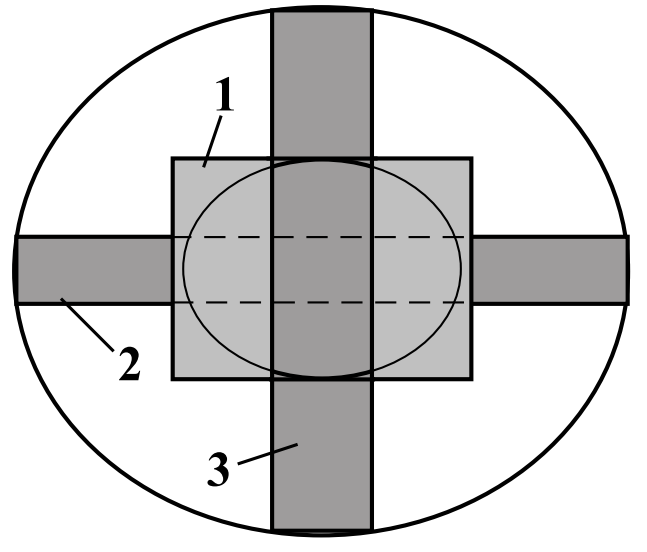

Figure 2. Study cell, top view

The study cell (fig. 2) is a model for any film impregnated capacitor. It consists of a plastic material (Teflon) in which two aluminium ribbons [2;3] are disposed at 90 degrees and separated by polypropylene films of $13.6 \mu \mathrm{m}$ thickness [1]. The study cell is filled with a dielectric liquid: the jarylec $\mathrm{C} 100$, used in powers capacitors. The Jarylec is a mixture of monobenzyltoluene and dibenzyltoluene, also with traces of tribenzyltoluene.

The impregnation's role is to fill any air pockets in the dielectric to avoid the initiation of a partial discharge at relatively low voltage. This type of insulation is used in capacitors for the compensation of reactive energy and therefore the partial discharge evolution, often, constitutes a precursory factor of their dielectric rupture.

\section{Experimental Results}

For a given temperature an increasing voltage level of $50 \mathrm{~V} / \mathrm{s}$ was applied until threshold voltage, leading to discharge appearance is reached. The voltage increase is continued to a value close to breakdown voltage. The acquisition system is continuously recording the partial discharge evolution at every voltage level. We have noted that the threshold voltage, over which partial discharge appears, for capacitor model tested at different temperatures, is practically identical and is situated around $5000 \mathrm{~V}$. The discharge regime is very variable and depends on time and applied voltage.

The experimental study has allowed us to identify two regimes of partial discharge which exists at different values of temperature. The transition from the first regime to the second results in an increase of the frequency and intensity of discharge. Figure 3 shows the evolution of the apparent charge $\mathrm{Q}$ in $\mathrm{pC}$ during the acquisition.

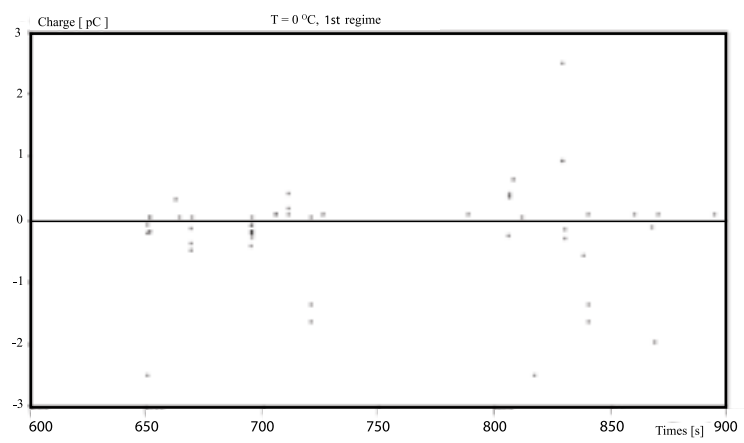

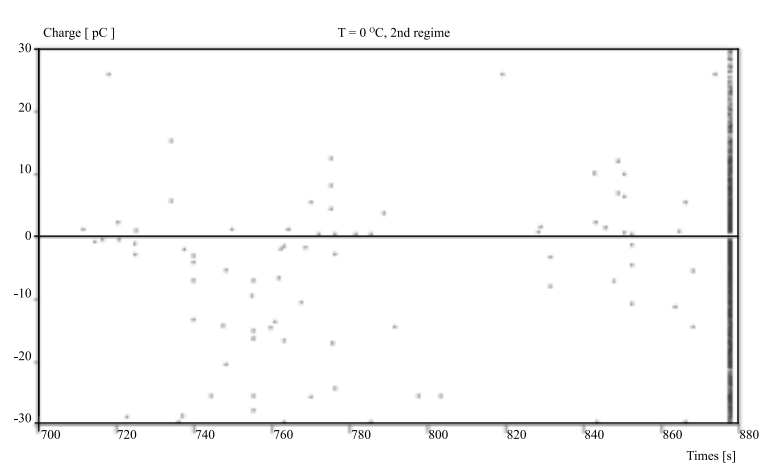
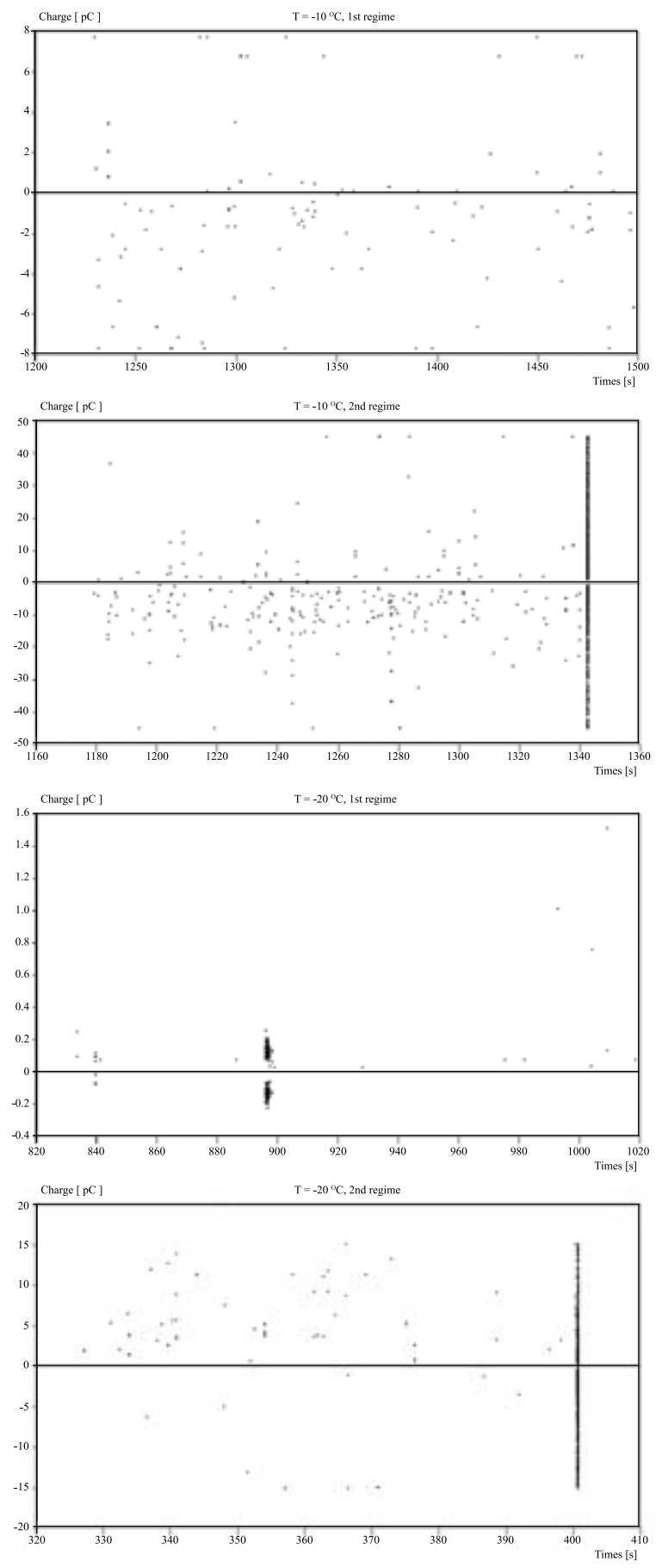

Figure 3. The evolution of the apparent charge $\mathrm{Q}$ in $\mathrm{pC}$ during the acquisition at different temperature. The left pictures of this figure correspond to the first regime of discharge and the right ones to the second regime 
The left picture of this figure corresponds to the first regime and the right one to the second regime. It is noticed that partial discharge appears randomly, meaning that the origin of the pulse is not identified.

The first regime begin from the voltage at which partial discharge appears (Va) to the transition voltage at $\mathrm{Vt}=1,5$. Va. This regime presents a small discharge frequency and doesn't drive to the breakdown of the capacitor model even after a very long time of voltage application. The second regime appears at $\mathrm{V}>\mathrm{Vt}(>7100$ $\mathrm{V})$. This regime is characterized by a high discharge frequency and more important amplitude than the first regime. This last regime conducts to the degradation and breakdown of the dielectric. In table 1, we compare the appearance voltage Va to the transition $\mathrm{Vt}$ and the breakdown voltage $\mathrm{Vb}$ at different temperatures.

Table 1. The appearance voltage Va, the transition voltage $\mathrm{Vt}$ and the breakdown voltage $\mathrm{Vb}$ at different temperature in the second regime

\begin{tabular}{cccc}
\hline $\mathrm{T}\left[{ }^{\circ} \mathrm{C}\right]$ & $\mathrm{Va}[\mathrm{V}]$ & $\mathrm{Vt}[\mathrm{V}]$ & $\mathrm{Vb}[\mathrm{V}]$ \\
\hline $0^{\circ}$ & 5000 & 7600 & 7800 \\
$-10^{\circ}$ & 5000 & 7400 & 7600 \\
$-20^{\circ}$ & 5000 & 7000 & 7200 \\
\hline
\end{tabular}

The figure 4 shows the evolution of the discharge frequency as function of voltage for different temperatures.

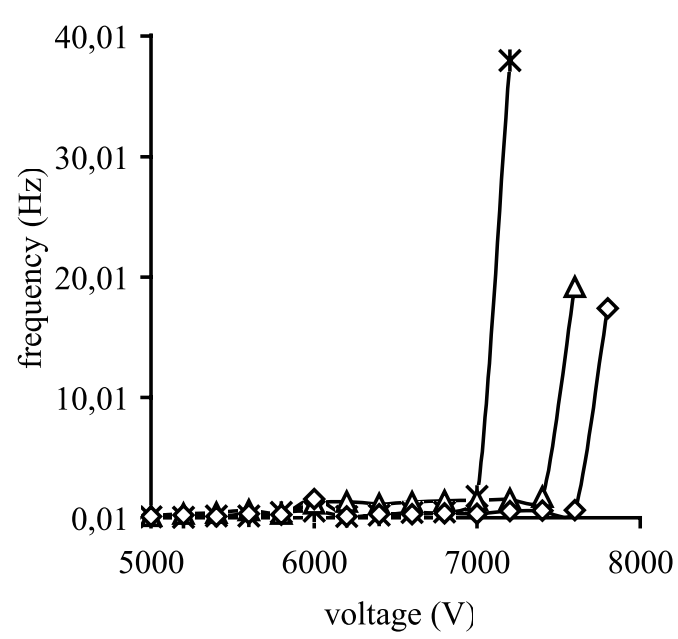

Figure 4. Variation of discharge frequency according to applied voltage at different temperatures. $\times:-20^{\circ} \mathrm{C} ; \triangle:-10^{\circ} \mathrm{C} ; \diamond: 0^{\circ} \mathrm{C}$

It is also observed that, for each temperature, the discharge frequency is so important than the applied voltage is high. Moreover, for the three temperatures, it clearly appears a transition in the discharge regime over which the number of discharges is becoming much more important. The effect of temperature on transition and breakdown voltage is given by the table 1 . It is noted that transition voltage to the second regime is decreased as the temperature decrease.

Figure 5 shows the evolution of the apparent charge as function of the applied voltage at different temperatures.

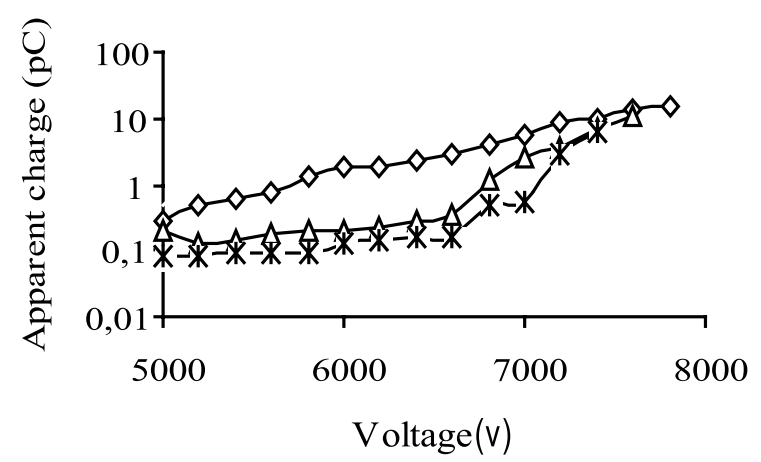

Figure 5. Variation of the apparent charge according to applied voltage at different temperatures. $\times:-20^{\circ} \mathrm{C} ; \triangle:-10^{\circ} \mathrm{C} ; \diamond: 0^{\circ} \mathrm{C}$.

It is observed that the influence of temperature on the apparent charge is not very important. Nevertheless, the transition voltage is particularly clear at low temperature. The average discharge frequency and its apparent charge are represented in table 2.

Table 2. Evolution of the discharge frequency and apparent charge in the first regime at different temperature

\begin{tabular}{cccc}
\hline $\mathrm{T}\left[{ }^{\circ} \mathrm{C}\right]$ & $\mathrm{Va}[\mathrm{V}]$ & Frequency $[\mathrm{Hz}]$ & $\mathrm{Q}[\mathrm{pC}]$ \\
\hline $0^{\circ}$ & 5000 & $0.11 \div 0.24$ & $0.28 \div 13.25$ \\
$-10^{\circ}$ & 5000 & $0.086 \div 0.76$ & $0.2 \div 6.72$ \\
$-20^{\circ}$ & 5000 & $0.086 \div 0.46$ & $0.08 \div 2.90$ \\
\hline
\end{tabular}

It is assumed that the first discharge regime corresponds to an electronic avalanche in the liquid phase. These avalanches will be able to form gaseous cavities in impregnating liquid which may develop the partial discharge. When increasing voltage the apparent charge increases slightly and the gaseous cavities should disappear rapidly, especially for $0^{\circ} \mathrm{C}$. When the voltage exceeds transition value, the discharge frequency and their number increase roughly. These discharges cause the dielectric breakdown.

The obtained results for low temperatures show a decrease in the transition voltage. This could be explained by the influence of the viscosity of the impregnating liquid. According to the bibliography, the jarylec viscosity is multiplied by 10 if we change temperature from 25 to -25 .

Another study on the influence of the viscosity of liquid on the air bubble shows that the life of this air bubbles in the liquid increases by increasing the viscosity. Therefore, the results confirm the role and the influence of viscosity on the gaseous phase. Thus, the probability of electrical discharges appearance in this phase also increases. This could have a direct effect on the development of a gaseous canal having rigidity much lower which leads to the breakdown.

Many studies have been conducted to find out the causes leading to the breakdown. In the present case of capacitors it was found that the greatest number of breakdown occurs in low temperatures and consequently in cold climates likely in the mornings of winter. 


\section{Conclusion}

Partial discharges recorded in the capacitor model made of impregnated solid insulation are random. The origin of the discharge is not identified; however the discharge regime varies according to the temperature and the voltage. We have shown that even for low temperatures, one record two partial discharge regimes whose second ends generally by the breakdown of the capacitor. It emerges that more temperature decrease more discharge frequency increase. It results that the breakdown appears at lower voltage levels in low temperatures. Similar results have been brought by
Hammal [8]. It is known that the liquid viscosity increases when the temperature decreases and this affect negatively the breakdown of the dielectrics liquids [9].

\section{Acknowledgement}

The experimental work has been performed at LEMD CNRS Grenoble and supported by the French-Algeria cooperation project CMEP/01 MDU523

\section{References}

1. M. Nemamcha, J.P. Gosse and B. Gosse, "Discharges in All-PP Film Model Capacitors", IEEE. Trans. on Elec. Insul. Vol. 28, No 3, pp. 315323, (1993).

2. H. Suzuki, K. Aihara, T. Okamoto, "Complex Behaviour of a Simple Partial Discharge Model”, A Letters Journal Exploring the Frontiers of Physics, Vol. 66, No 1, pp. 28-34, (2004).

3. C.G. Karagiannopoulos, “A Model For Dielectrics Experiencing Partial Discharges Under High Electrics Fields", Journal of Electrostatics, Vol. 65, No 8, pp. 535-541, (2007).

4. M. Nemamcha, J.P. Gosse and B. Gosse, "Effect of Partial Discharges on Impregnated Polypropylene Films", IEEE. Trans. on Dielec. and Elec. Insul. Vol. 1, No 4, pp. 578-584, (1994).

5. M. Pompili, C. Mazzeti, "Partial Discharge Behavior in Switching-surgeaged oil-paper Capacitor Bushing Insulation”, IEEE. Trans. on Dielec. and Elec. Insul., Vol. 9, No 1, pp. 104-111, (2002).
6. A. Covallini, G.C. Montanari and F. Giani, “Analysis of Partial Discharge Phenomena in Paper Oil Insulation Systems as a Basis for Risk Assessment Evaluation" in Proc. IEEE. Int. Conf. on Dielectric Liquids, pp. 241244, (Portugal), (2005).

7. M. Nemamcha, J.P. Gosse and C. Marteau, "Monitoring of Partial Discharge in Capacitor Models with Impregnated Polypropylene Films", in Proc. $4^{\text {th }}$ Int. Conf. on Conduction and Breakdown in Solid Dielectrics, pp. 205-208, (Italy), (1992).

8. R. Hammal, P. Rain, J.P. Gosse and C. Hantouche, "Characterisation of Partial Discharge in Impregnated Capacitor", in Proc. $12^{\text {th }}$ Int. Conf. on Conduction and Breakdown in Dielectric Liquids, pp. 171-174, (Rome), (1996).

9. F. Jomni, A. Denat, N. Bonifaci and M. Nur, "Electrical Process Study of Hydrodynamic in the Dielectrics Aliphatics and Aromatic in Divergent Fields". $2^{\text {eme }}$ Conf. Nat. sur la Haute Tension (CNHT). Tizi-Ouzou (Algeria), (1997). 